\title{
Development of A-DA'D-A Small-Molecular Acceptors Based on a 6,12- Dihydro-diindolo[1,2-b:10,20-e]pyrazine Unit for Efficient As-Cast Polymer Solar Cells
}

Li Chen, ${ }^{a}$ Min Zeng, ${ }^{a}$ Xuejiao Tang, ${ }^{a}$ Chao Weng ${ }^{a^{*}}$, Songting Tan, ${ }^{a}$ and Ping Shen ${ }^{{ }^{*}}$

${ }^{a}$ Key Laboratory for Green Organic Synthesis and Application of Hunan Province, Key Laboratory of Environmentally Friendly Chemistry and Application of Ministry of Education, College of Chemistry, Xiangtan University, Xiangtan 411105, China.

E-mail: wengc2013@163.com; shenping802002@163.com

\section{Materials Synthesis and Structural Characterization}

Synthesis of Compound 5. Compound 5 based on IPY was synthesized by a Suzuki coupling reaction. Compound 4 (3.33 g, $3.50 \mathrm{mmol}$ ), ethyl 2-bromothiophene-3-carboxylate (2.45 g, $\left.10.4 \mathrm{mmol}), \mathrm{Pd}_{(\mathrm{PPh}}\right)_{4}(120$ $\mathrm{mg}), 10 \mathrm{~mL} \mathrm{~K}_{2} \mathrm{CO}_{3}$ aqueous solution $(2 \mathrm{M})$ and two drops of trioctylmethylammonium chloride were added into a $250 \mathrm{~mL}$ round bottom flask. The reaction system was carried out vacuuming and backfilling with argon three times before the addition of dry toluene $(50 \mathrm{~mL})$. The resultant mixture was heated slowly to $120^{\circ} \mathrm{C}$ and stirred for overnight. The reaction system was allowed to drop to room temperature and the mixture was extracted with dichloromethane. The organic layer was washed several times with water and dried over anhydrous $\mathrm{Na}_{2} \mathrm{SO}_{4}$. After the removal of dichloromethane, Compound $\mathbf{5}$ was produced through silica gel column chromatography using a mixture of petroleum ether/dichloromethane as eluent (3.13 g, yield 88.2\%). ${ }^{1} \mathrm{H}$ NMR $\left(400 \mathrm{MHz}, \mathrm{CDCl}_{3}, \delta / \mathrm{ppm}\right): 8.12(\mathrm{~d}, J=8.0 \mathrm{~Hz}, 2 \mathrm{H}), 7.58(\mathrm{~d}, J=4.0 \mathrm{~Hz}, 2 \mathrm{H}), 7.55(\mathrm{~s}, 2 \mathrm{H}), 7.29(\mathrm{~d}$, $J=8.0 \mathrm{~Hz}, 2 \mathrm{H}), 7.26(\mathrm{~d}, J=4.0 \mathrm{~Hz}, 2 \mathrm{H}), 4.25-4.20(\mathrm{~m}, 4 \mathrm{H}), 2.31-2.25(\mathrm{~m}, 4 \mathrm{H}), 2.06-2.00(\mathrm{~m}, 4 \mathrm{H}), 1.35-1.07$ $(\mathrm{m}, 46 \mathrm{H}), 0.97-0.77(\mathrm{~m}, 14 \mathrm{H}), 0.71-0.64(\mathrm{~m}, 6 \mathrm{H}) .{ }^{13} \mathrm{C} \mathrm{NMR}\left(100 \mathrm{MHz}, \mathrm{CDCl}_{3}, \delta / \mathrm{ppm}\right): 163.75,163.36$, $151.46,150.89$, 150.04, 139.13, 134.21, 130.15, 129.16, 128.69, 124.62, 124.14, 120.66, 77.37, 77.05, 76.73, 
60.51, 53.08, 38.52, 31.81, 29.93, 29.19, 23.98, 22.60, 14.24, 14.08. MS (MALDI-TOF, $m / z) \mathrm{C}_{64} \mathrm{H}_{88} \mathrm{~N}_{2} \mathrm{O}_{4} \mathrm{~S}_{2}$ : calculated: 1013.540; found: 1014.635.

Synthesis of IPYT. A solution of 1-bromo-4-hexylxybenzene (2.90 g, $12.0 \mathrm{mmol})$ in THF (20 mL) was slowly added $4.60 \mathrm{~mL} n$-BuLi $\left(2.4 \mathrm{M}\right.$ in THF) at $-78^{\circ} \mathrm{C}$ under $\mathrm{Ar}$ atmosphere. After stirring at $-78^{\circ} \mathrm{C}$ for $2 \mathrm{~h}$, a THF solution of Compound $5(2.03 \mathrm{~g}, 2.00 \mathrm{mmol})$ was slowly added into this reaction system and then the mixture was stirred overnight at room temperature. The reaction was quenched by adding water and extracted with dichloromethane. The organic layer was washed several times with water and dried over anhydrous $\mathrm{Na}_{2} \mathrm{SO}_{4}$. After the removal of dichloromethane, the residue was shifted into a $250 \mathrm{~mL}$ three-neck flask, then glacial acetic acid $(40 \mathrm{~mL})$ and a small amount of concentrated $\mathrm{H}_{2} \mathrm{SO}_{4}(1 \mathrm{~mL})$ were added. Then the mixture was kept refluxing for $4 \mathrm{~h}$. After cooling to room temperature, the reaction was quenched and extracted with ethyl acetate. The organic phase was washed with brine and dried over anhydrous $\mathrm{Na}_{2} \mathrm{SO}_{4}$. Finally, the pure IPYT was obtained as a blue-yellow solid (1.25 g, 40.8\%) after the crude produce was subjected to treatment through silica gel column chromatography using an eluent of petroleum ether/dichloromethane. ${ }^{1} \mathrm{H}$ NMR (400 $\left.\mathrm{MHz}, \mathrm{CDCl}_{3}, \delta / \mathrm{ppm}\right): 8.05$ (s, 2H), 7.46 (s, 2H), 7.33 (d, J=4.0 Hz, 2H), 7.23-7.22 (m, 8H), 7.10-7.07 (m, $8 \mathrm{H}), 7.04(\mathrm{~d}, J=8.0 \mathrm{~Hz}, 2 \mathrm{H}), 2.58-2.54(\mathrm{~m}, 8 \mathrm{H}), 2.21-2.16(\mathrm{~m}, 4 \mathrm{H}), 2.02-1.96(\mathrm{~m}, 4 \mathrm{H}), 1.61-1.55(\mathrm{~m}, 8 \mathrm{H})$, 1.37-1.29 (m, 24H), 1.16-1.07 (m, 40H), 0.89-0.85 (m, 12H), 0.78-0.74 (m, 14H), 0.65-0.63 (m, 6H). ${ }^{13} \mathrm{C}$ NMR (100 MHz, $\left.\mathrm{CDCl}_{3}, \delta / \mathrm{ppm}\right): 163.34,156.92,153.20,151.24,150.51,142.19,141.33,141.16,138.32$, 136.96, 128.21, 128.17, 128.08, 123.39, 118.96, 113.92, 77.33, 77.01, 76.70, 62.78, 52.66, 38.61, 35.58, 31.73, 31.32, 29.91, 29.18, 29.16, 23.96, 22.60, 22.56, 14.08, 14.04. MS (MALDI-TOF, m/z) $\mathrm{C}_{108} \mathrm{H}_{144} \mathrm{~N}_{2} \mathrm{~S}_{2}$ : calculated: 1534.470 ; found: 1534.870 .

Synthesis of IPYT-CHO. Under an Ar atmosphere, IPYT $(1.38 \mathrm{~g}, 0.90 \mathrm{mmol})$ and $40 \mathrm{~mL}$ of dried DMF were added in to a $250 \mathrm{~mL}$ three-necked round bottom flask. This solution was cooled to $0{ }^{\circ} \mathrm{C}$ and stirred, then $1.4 \mathrm{~mL}$ of $\mathrm{POCl}_{3}$ was added dropwise. The mixture was stirred for $0.5 \mathrm{~h}$ at room temperature, and then allowed to heat up to $100{ }^{\circ} \mathrm{C}$ and kept stirring for $12 \mathrm{~h}$. After cooling to room temperature, the reaction mixture was poured into $100 \mathrm{~mL}$ of $1 \mathrm{M} \mathrm{NaOH}$ solution and extracted with dichloromethane. The organic phase was washed with brine and dried over anhydrous $\mathrm{Na}_{2} \mathrm{SO}_{4}$. Finally, the pure IPYT-CHO was gained as an orange solid $(1.23 \mathrm{~g}, 86.0 \%)$ after the crude produce was subjected to treatment through silica gel column chromatography using an eluent of petroleum ether/dichloromethane. ${ }^{1} \mathrm{H}$ NMR $\left(400 \mathrm{MHz}, \mathrm{CDCl}_{3}, \delta / \mathrm{ppm}\right)$ : $9.87(\mathrm{~s}, 2 \mathrm{H}), 8.11(\mathrm{~s}, 2 \mathrm{H}), 7.70(\mathrm{~s}, 2 \mathrm{H}), 7.62(\mathrm{~s}, 2 \mathrm{H}), 7.23-7.21(\mathrm{~m}, 8 \mathrm{H}), 7.13-7.11(\mathrm{~m}, 8 \mathrm{H}), 2.60-2.56(\mathrm{~m}, 8 \mathrm{H})$, 2.25-2.18 (m, 4H), 2.07-1.99(m, 4H), 1.63-1.56 (m, 8H), 1.43-1.27 (m, 24H), 1.15-1.07 (m, 40H), 0.89-0.85 $(\mathrm{m}, 12 \mathrm{H}), 0.80-0.74(\mathrm{~m}, 14 \mathrm{H}), 0.66-0.60(\mathrm{~m}, 6 \mathrm{H}) .{ }^{13} \mathrm{C} \mathrm{NMR}\left(100 \mathrm{MHz}, \mathrm{CDCl}_{3}, \delta / \mathrm{ppm}\right): 182.95,164.01$, 
157.02 , 154.35, 151.27, 151.07, 150.93, 146.13, 141.97, 141.13, 139.28, 136.81, 132.32, 128.50, 127.89, 119.28, 115.76, 77.33, 77.04, 76.70, 63.00, 52.94, 38.52, 35.56, 31.70, 31.32, 29.82, 29.14, 29.11, 23.98, 22.59, 22.55, 14.08, 14.03. MS (MALDI-TOF, $m / z$ ) $\mathrm{C}_{110} \mathrm{H}_{144} \mathrm{~N}_{2} \mathrm{O}_{2} \mathrm{~S}_{2}$ : calculated: 1590.490; found: 1590.601. Synthesis of the target SMA IPYT-IC. Under an Ar atmosphere, a mixture solution combined with compound IPYT-CHO (0.89 g, $0.56 \mathrm{mmol})$, IC (0.43 g, $2.24 \mathrm{mmol})$, pyridine (1 mL), and chloroform (40 $\mathrm{mL}$ ) was added into a $100 \mathrm{~mL}$ round bottom flask and then kept stirring and refluxing for $12 \mathrm{~h}$. After cooling to room temperature, the mixture was poured into a large amount of methanol to form a black solid as the crude product of IPYT-IC, which was further purified through silica gel column chromatography with petroleum ether/THF as eluent $(0.43 \mathrm{~g}, 39.6 \%) .{ }^{1} \mathrm{H} \mathrm{NMR}\left(400 \mathrm{MHz}, \mathrm{CDCl}_{3}, \delta / \mathrm{ppm}\right): 8.93$ (s, 2H), 8.70 (d, $J$ $=8.0 \mathrm{~Hz}, 2 \mathrm{H}), 8.14(\mathrm{~s}, 2 \mathrm{H}), 7.94(\mathrm{~d}, J=8.0 \mathrm{~Hz}, 2 \mathrm{H}), 7.76-7.73(\mathrm{~m}, 8 \mathrm{H}), 7.24-7.22(\mathrm{~m}, 8 \mathrm{H}), 7.15-7.13(\mathrm{~m}, 8 \mathrm{H})$, 2.61-2.57 (m, 8H), 2.24-2.16 (m, 4H), 2.09-2.03 (m, 4H), 1.65-1.56 (m, 8H), 1.43-1.26 (m, 24H), 1.17-1.09 $(\mathrm{m}, 40 \mathrm{H}), 0.89-0.86(\mathrm{~m}, 12 \mathrm{H}), 0.78-0.70(\mathrm{~m}, 14 \mathrm{H}), 0.69-0.62(\mathrm{~m}, 6 \mathrm{H}) .{ }^{13} \mathrm{C} \mathrm{NMR}\left(100 \mathrm{MHz}, \mathrm{CDCl}_{3}, \delta / \mathrm{ppm}\right)$ : 188.42 , 164.69, 160.48, 159.85, 157.88, 155.50, 151.51, 151.26, 142.12, 140.98, 140.89, 140.58, 139.97, $139.74,138.63,136.97,136.93,135.14,134.46,128.61,127.94,125.34,123.77,122.00,119.53,116.68$, $114.69,77.34,77.03,76.71,69.06,63.03,52.96,38.43,35.59,31.71,31.33,29.89,29.15,24.11,22.59,22.57$, 14.09, 14.04. MS (MALDI-TOF, $m / z) \mathrm{C}_{134} \mathrm{H}_{152} \mathrm{~N}_{6} \mathrm{O}_{2} \mathrm{~S}_{2}$ : calculated: 1942.850; found: 1942.027.

Synthesis of the target SMA IPYT-ICF. Under an Ar atmosphere, a mixture solution combined with compound IPYT-CHO (0.87 g, $0.55 \mathrm{mmol})$, ICF (0.51 g, $2.20 \mathrm{mmol})$, pyridine (1 mL), and chloroform (30 $\mathrm{mL}$ ) was added to a $100 \mathrm{~mL}$ round bottom flask and then kept stirring and refluxing for $12 \mathrm{~h}$. After cooling to room temperature, the mixture was poured into a large amount of methanol to form a black solid as the crude product of IPYT-ICF, which was further purified through silica gel column chromatography with petroleum ether/tetrahydrofuran as eluent (0.45 g, 40.6\%). ${ }^{1} \mathrm{H}$ NMR (400 MHz, $\left.\mathrm{CDCl}_{3}, \delta / \mathrm{ppm}\right): 8.92$ (s, 2H), 8.58-8.54 $(\mathrm{m}, 2 \mathrm{H}), 8.14(\mathrm{~s}, 2 \mathrm{H}), 7.77-7.69(\mathrm{~m}, 6 \mathrm{H}), 7.23-7.21(\mathrm{~m}, 8 \mathrm{H})$, 7.15-7.13 (m, 8H), 2.60-2.56 (m, 8H), 2.23-2.16 (m, 4H), 2.09-2.02 (m, 4H), 1.64-1.57 (m, 8H), 1.36-1.29 (m, 24H), 1.16-1.08 (m, 40H), 0.87-0.84 (m, 12H), 0.77-0.74 (m, 14H), 0.68-0.62 (m, 6H). $\left.{ }^{13} \mathrm{C} \mathrm{NMR} \mathrm{(100} \mathrm{MHz,} \mathrm{CDCl}_{3}, \delta / \mathrm{ppm}\right): 186.05,164.80,160.93,158.39$, 158.20, 155.71, 151.62, 151.28, 142.23, 140.93, 140.82, 140.74, 140.32, 138.83, 136.80, 128.65, 127.91, 121.06, 119.61, 116.86, 114.29, 114.22, 100.53, 77.34, 77.02, 76.70, 69.58, 63.04, 53.01, 38.43, 35.58, 31.71, 31.32, 29.86, 29.14, 24.10, 22.59, 22.56, 14.08, 14.03. $\left.{ }^{19} \mathrm{~F} \mathrm{NMR} \mathrm{(376} \mathrm{MHz,} \mathrm{CDCl}_{3}, \delta / \mathrm{ppm}\right):-122.56(\mathrm{~d}, J=$ 19.1 Hz), -123.66 (d, $J=19.3 \mathrm{~Hz})$. MS (MALDI-TOF, m/z) $\mathrm{C}_{134} \mathrm{H}_{148} \mathrm{~F}_{4} \mathrm{~N}_{6} \mathrm{O}_{2} \mathrm{~S}_{2}$ : calculated: 2014.810; found: 2014.881. 


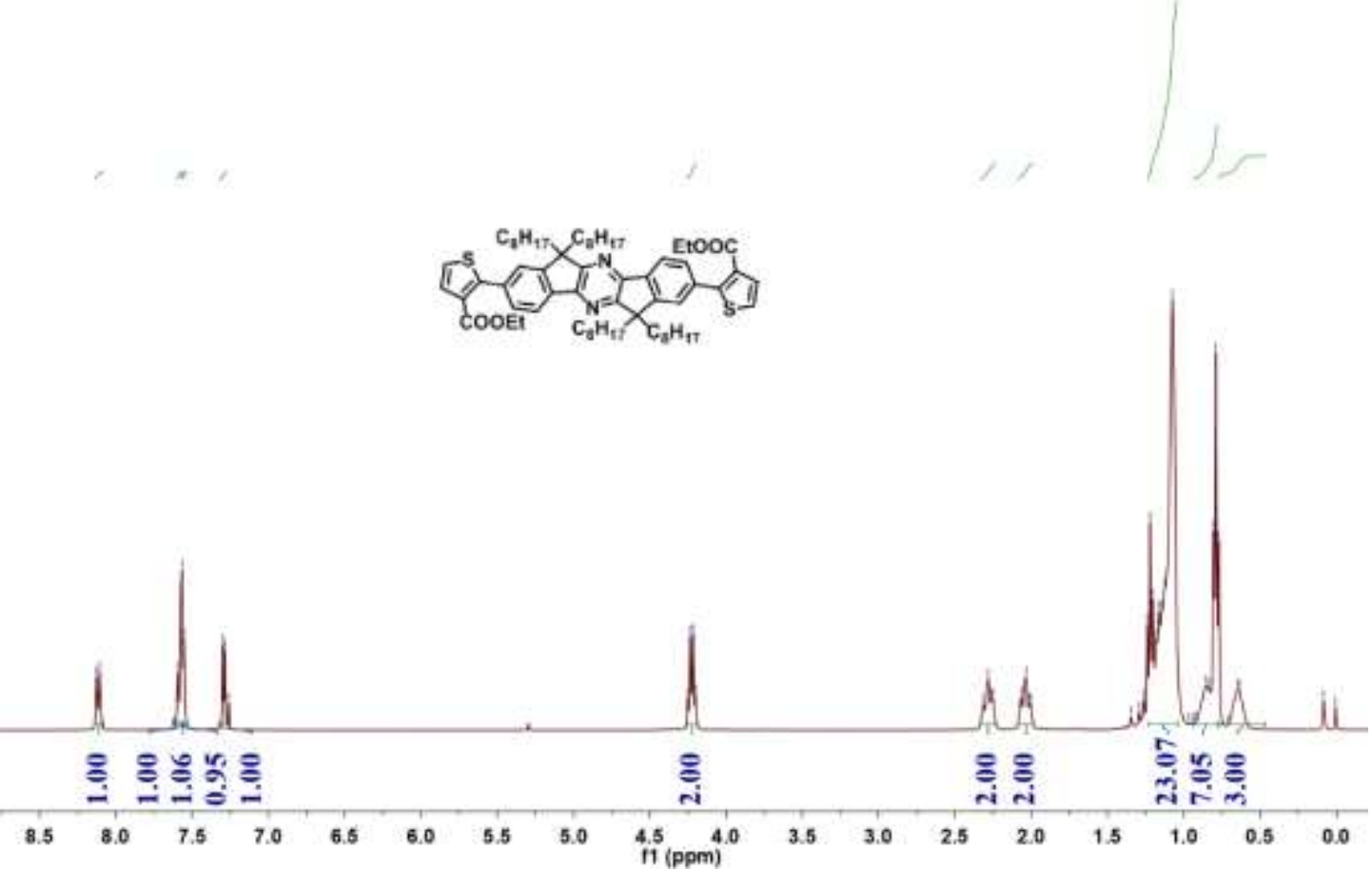

Figure S1. The ${ }^{1} \mathrm{H}$ NMR spectrum $\left(400 \mathrm{MHz}, \mathrm{CDCl}_{3}\right)$ of compound 5 .

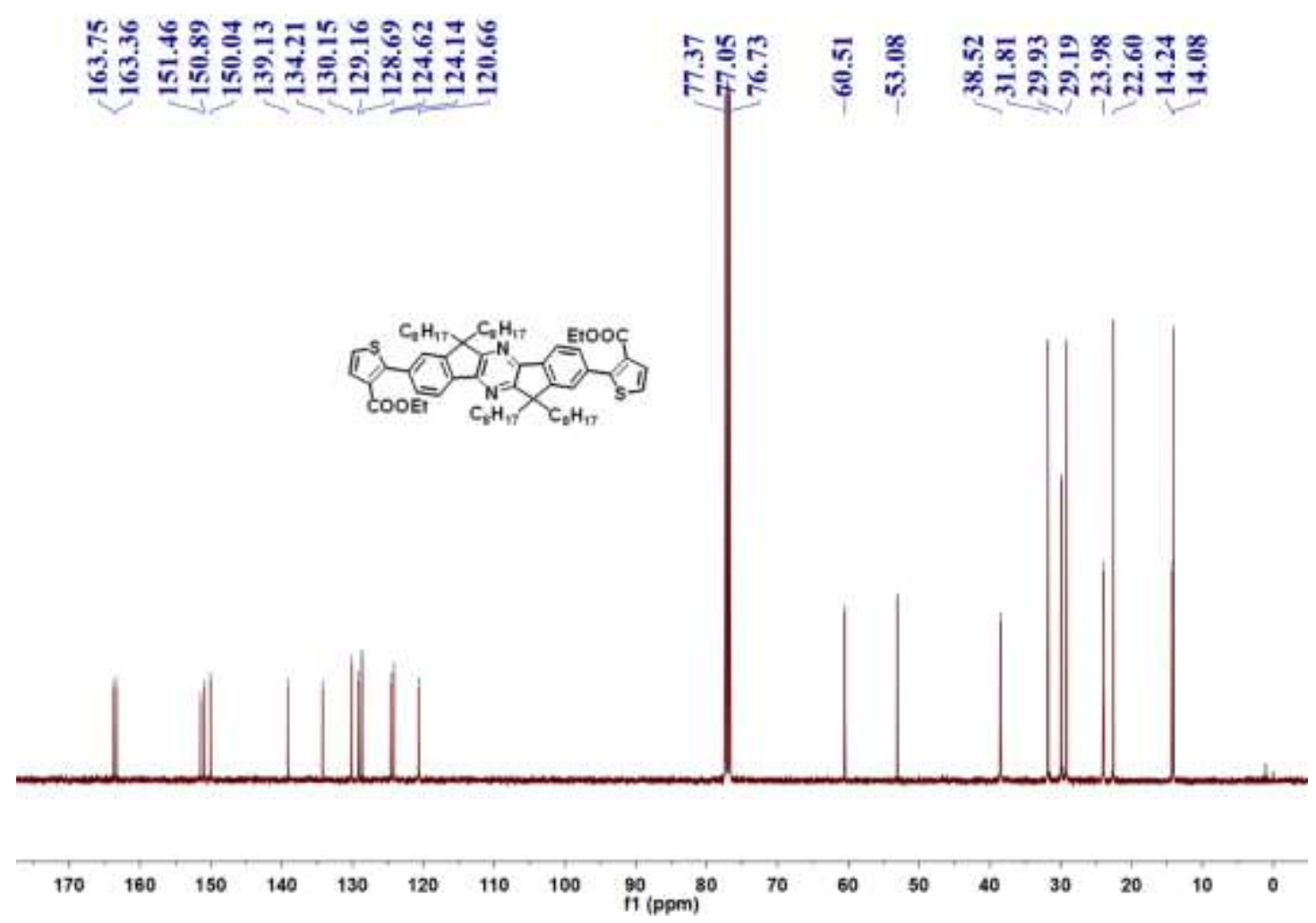

Figure S2. The ${ }^{13} \mathrm{C}$ NMR spectrum $\left(400 \mathrm{MHz}, \mathrm{CDCl}_{3}\right)$ of compound $\mathbf{5}$. 


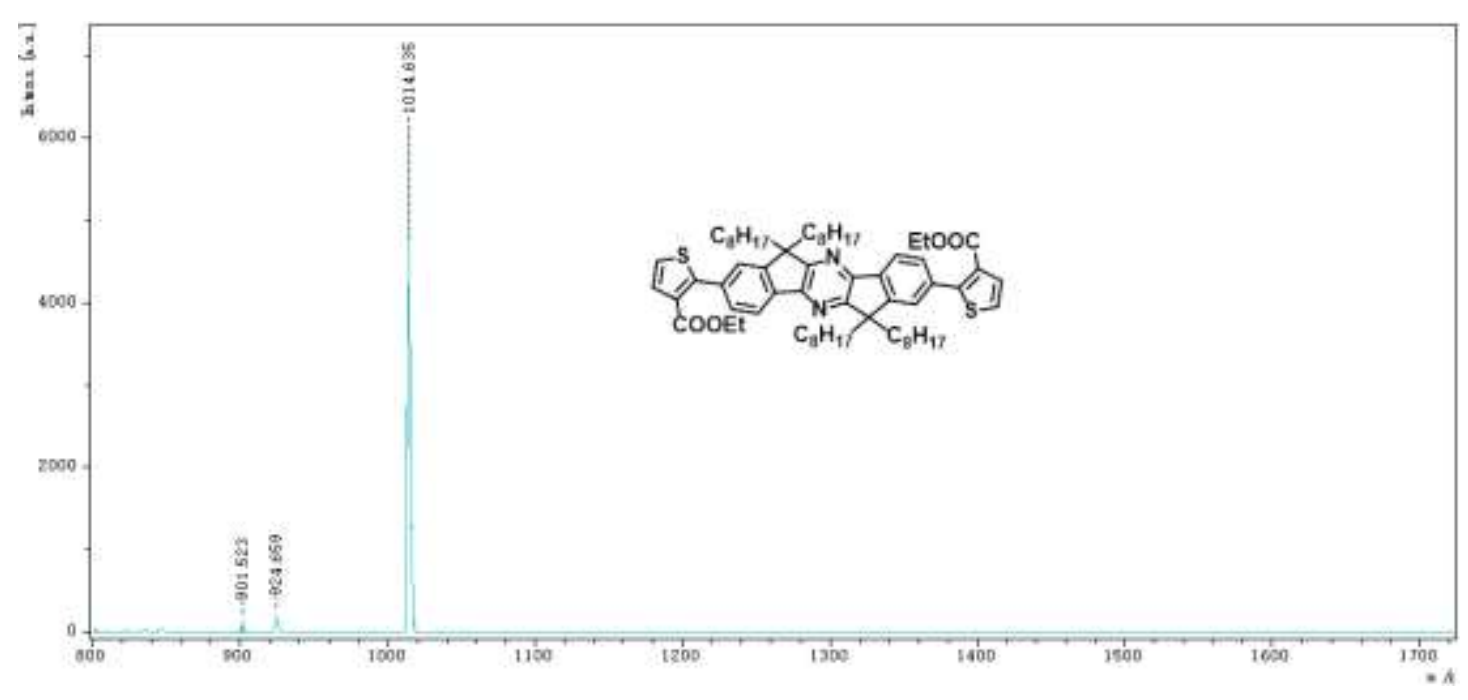

Figure S3. The MALDI-TOF mass spectrum of compound 5.

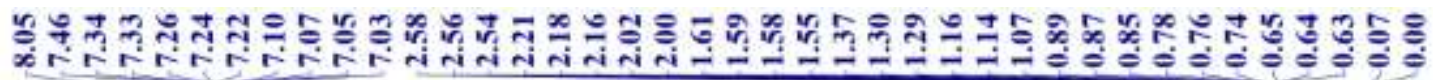

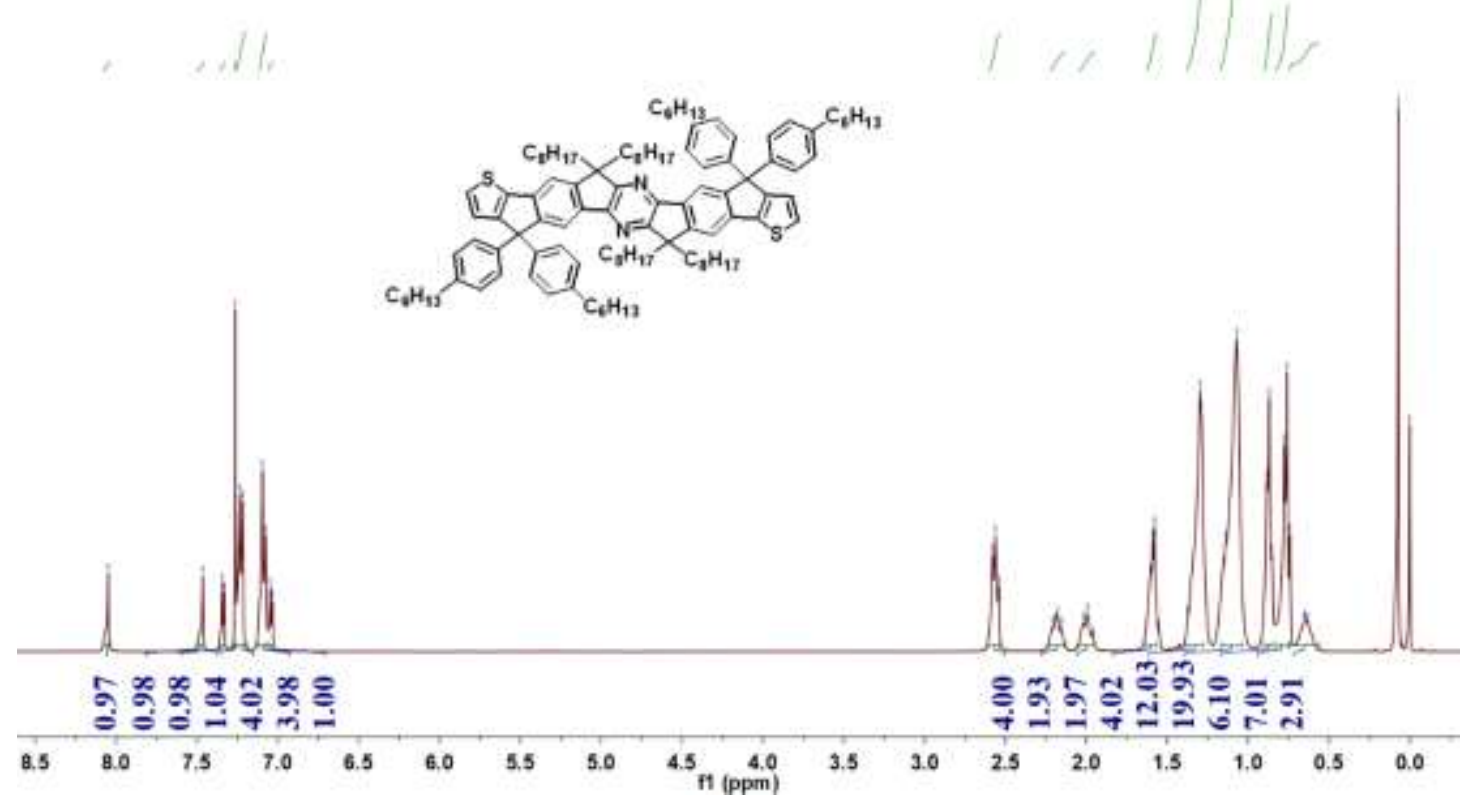

Figure S4. The ${ }^{1} \mathrm{H}$ NMR spectrum $\left(400 \mathrm{MHz}, \mathrm{CDCl}_{3}\right)$ of compound IPYT. 

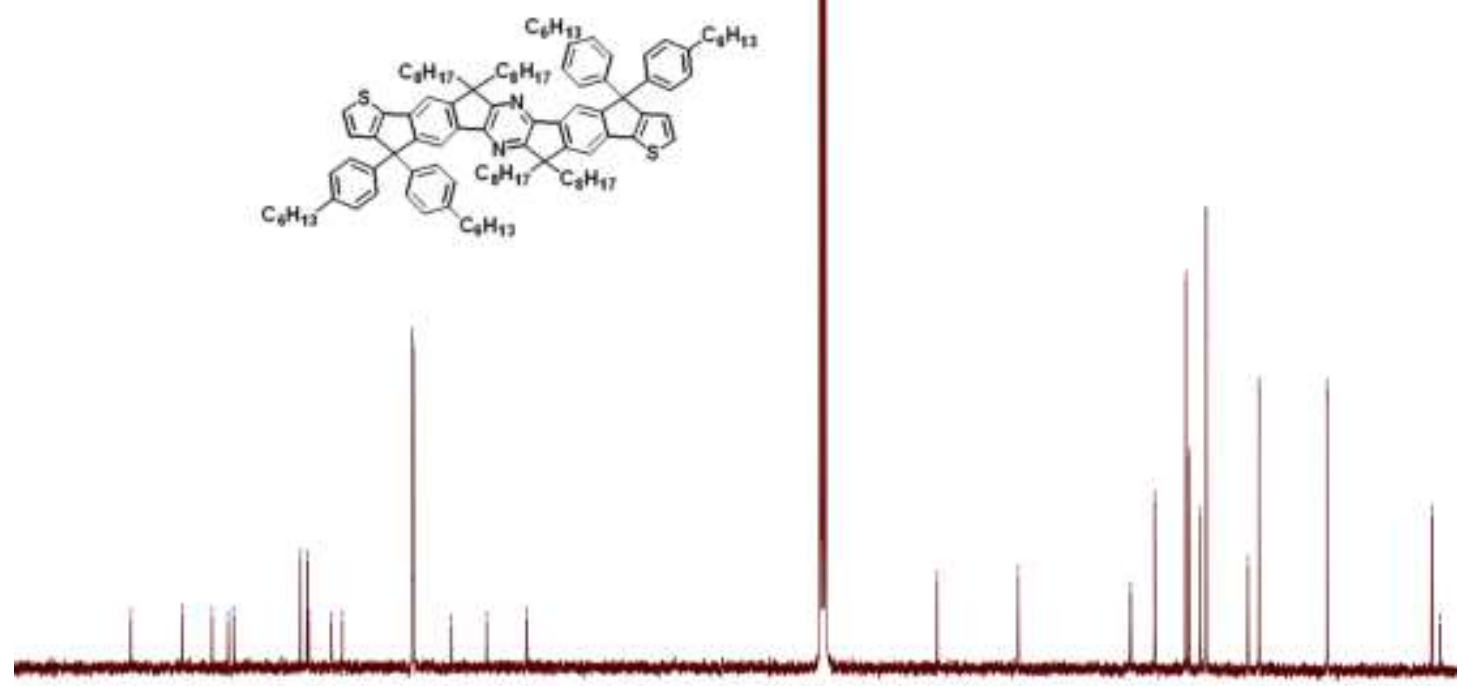

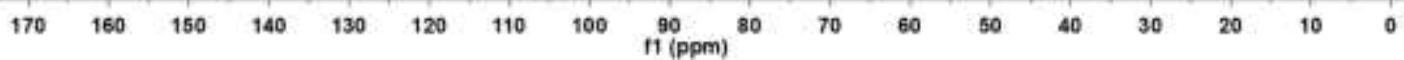

Figure S5. The ${ }^{13} \mathrm{C}$ NMR spectrum $\left(400 \mathrm{MHz}, \mathrm{CDCl}_{3}\right)$ of compound IPYT.

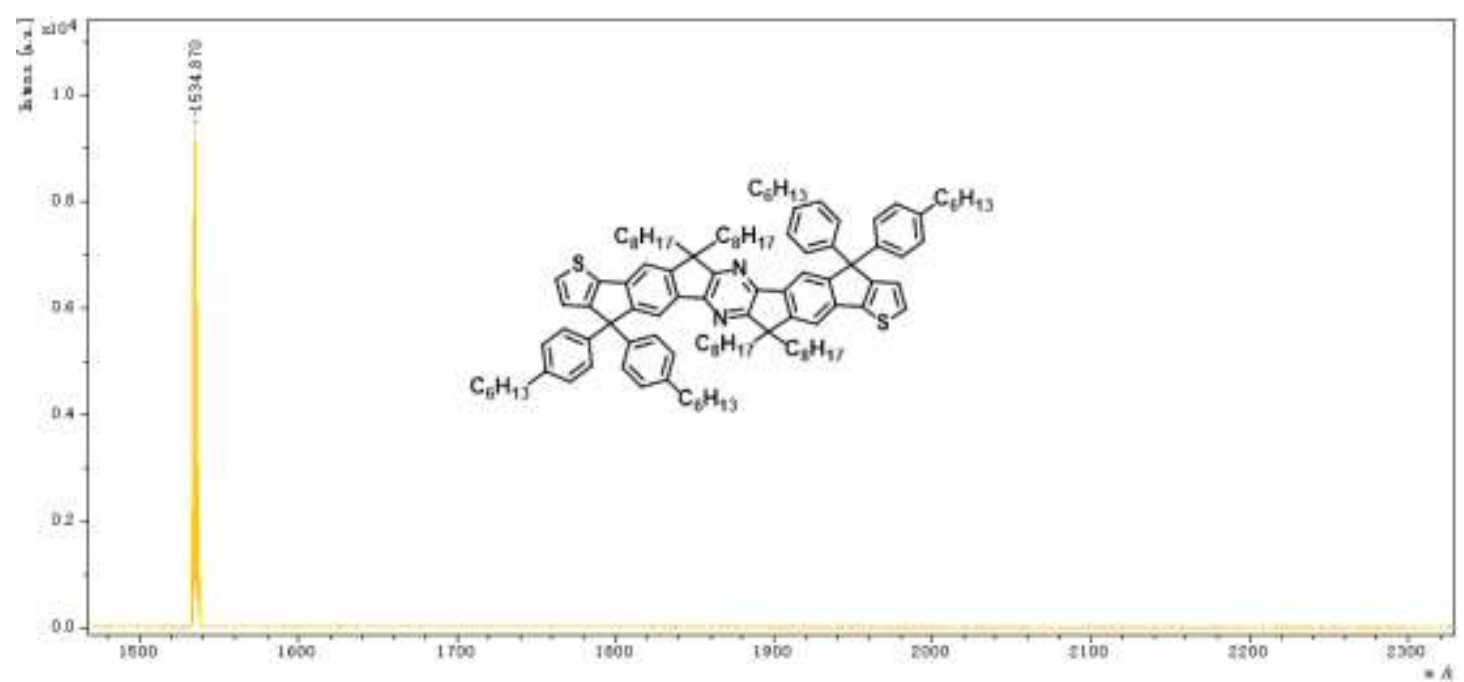

Figure S6. The MALDI-TOF mass spectrum of compound IPYT. 


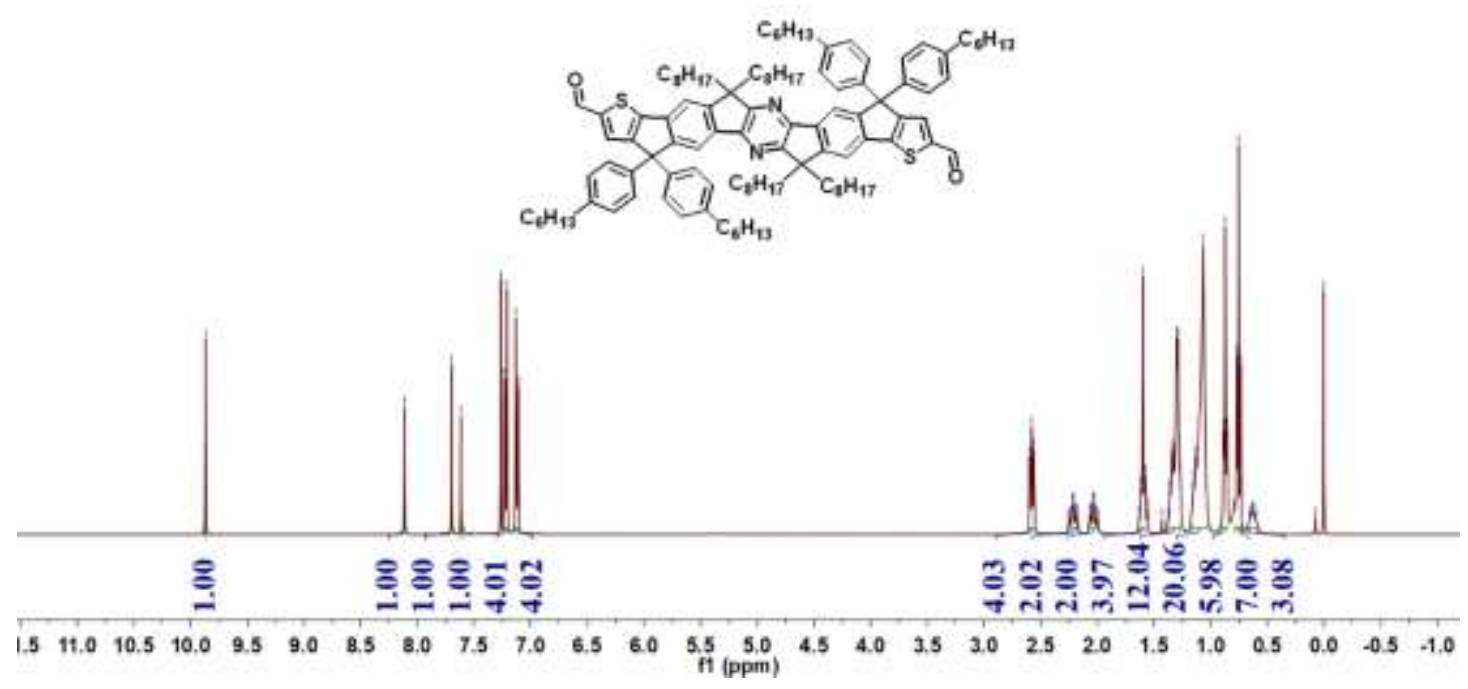

Figure S7. The ${ }^{1} \mathrm{H}$ NMR spectrum (400 MHz, $\left.\mathrm{CDCl}_{3}\right)$ of compound IPYT-CHO.

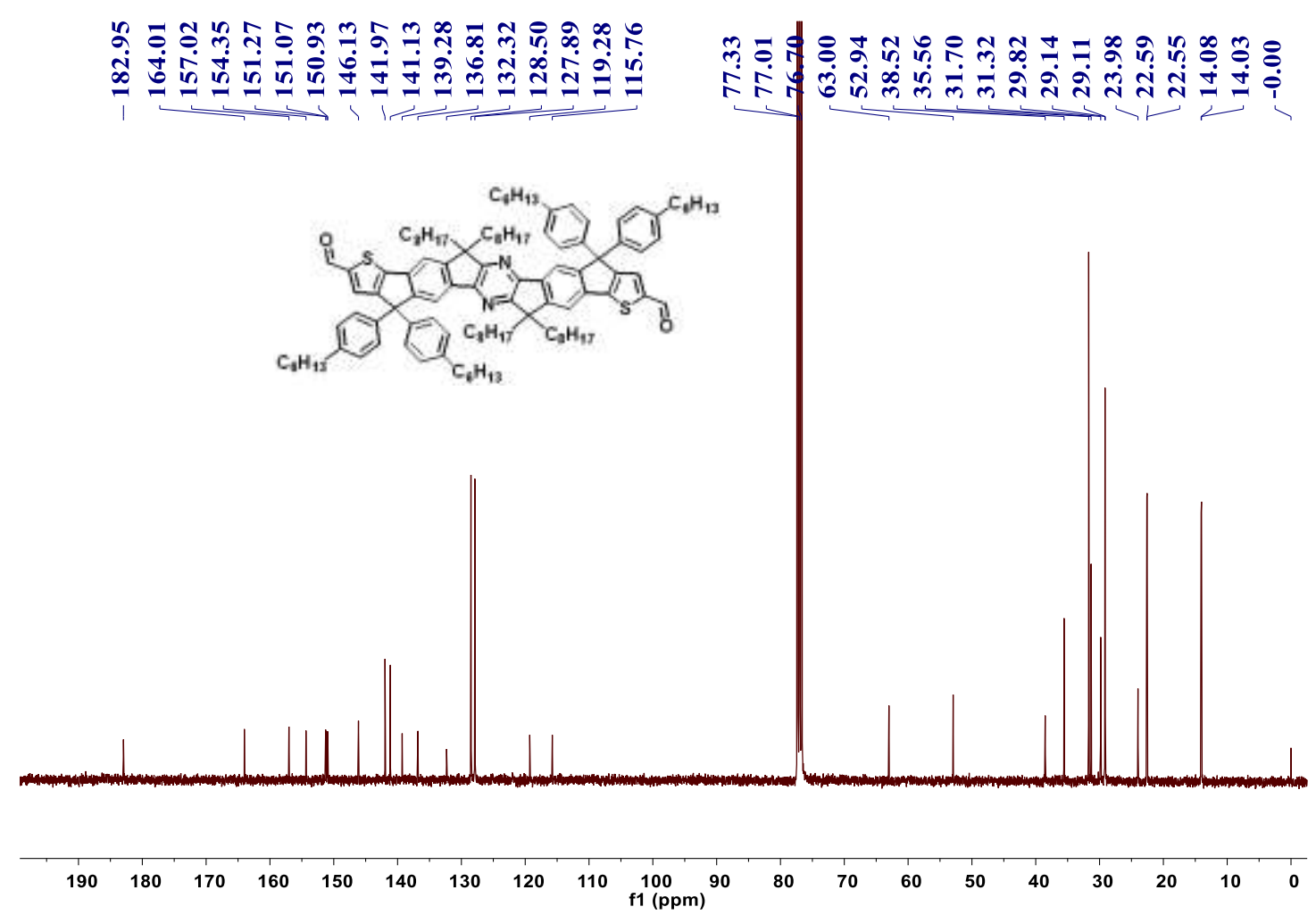

Figure S8. The ${ }^{13} \mathrm{C}$ NMR spectrum $\left(400 \mathrm{MHz}, \mathrm{CDCl}_{3}\right)$ of compound IPYT-CHO. 


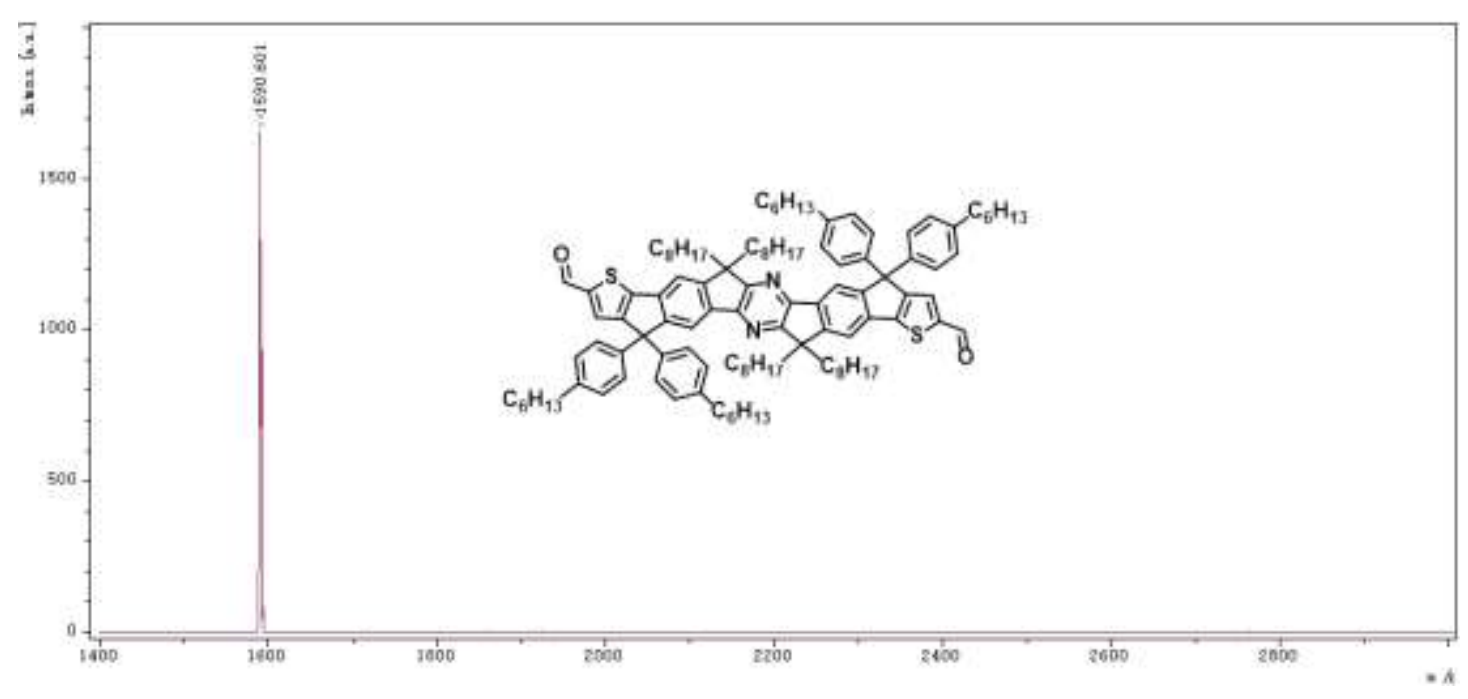

Figure S9. The MALDI-TOF mass spectrum of compound IPYT-CHO.

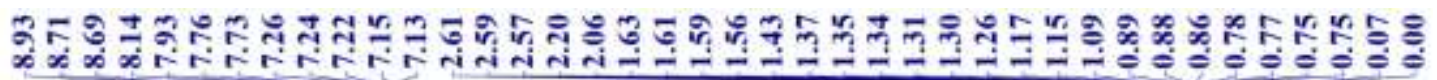

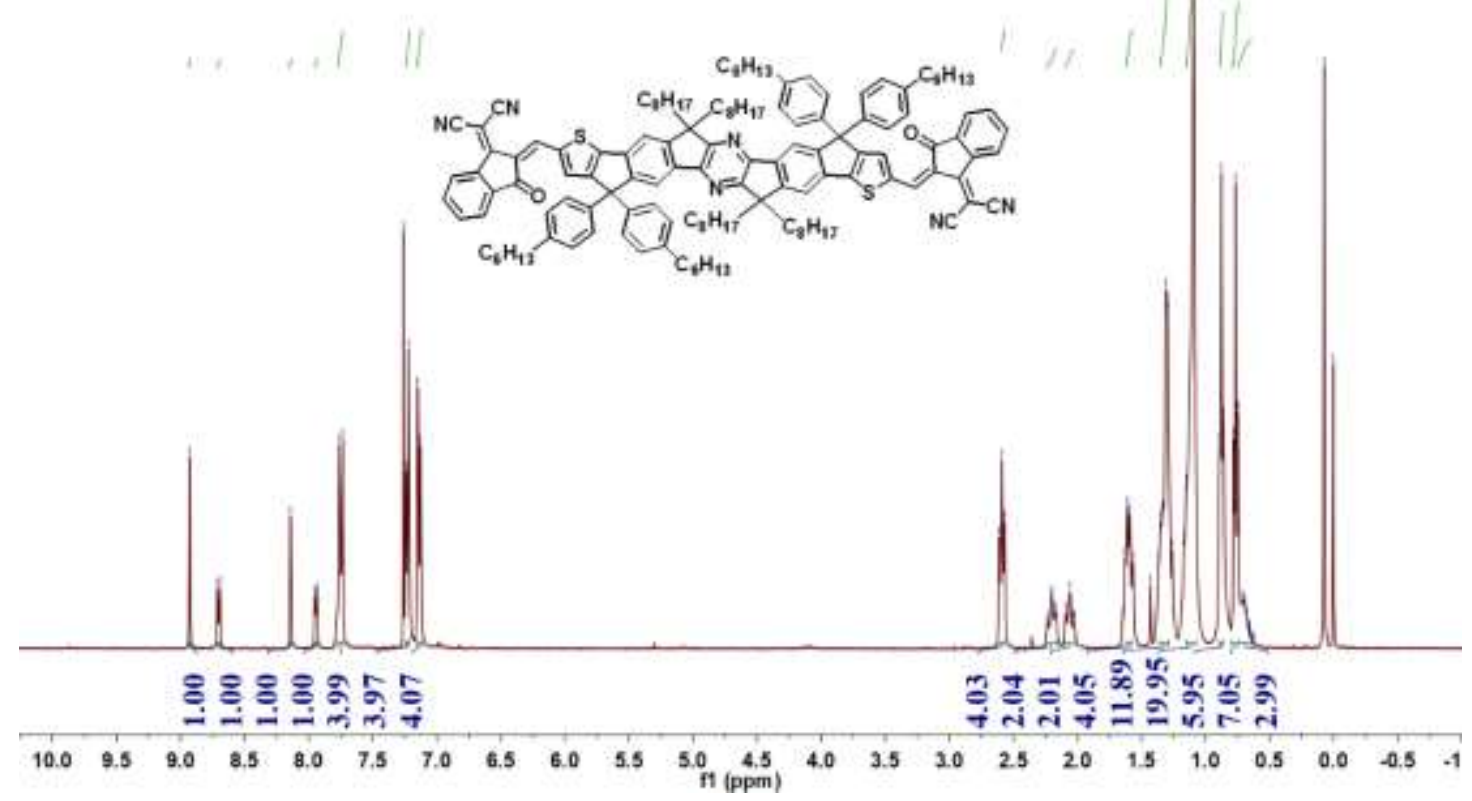

Figure S10. The ${ }^{1} \mathrm{H}$ NMR spectrum (400 MHz, $\left.\mathrm{CDCl}_{3}\right)$ of IPYT-IC. 


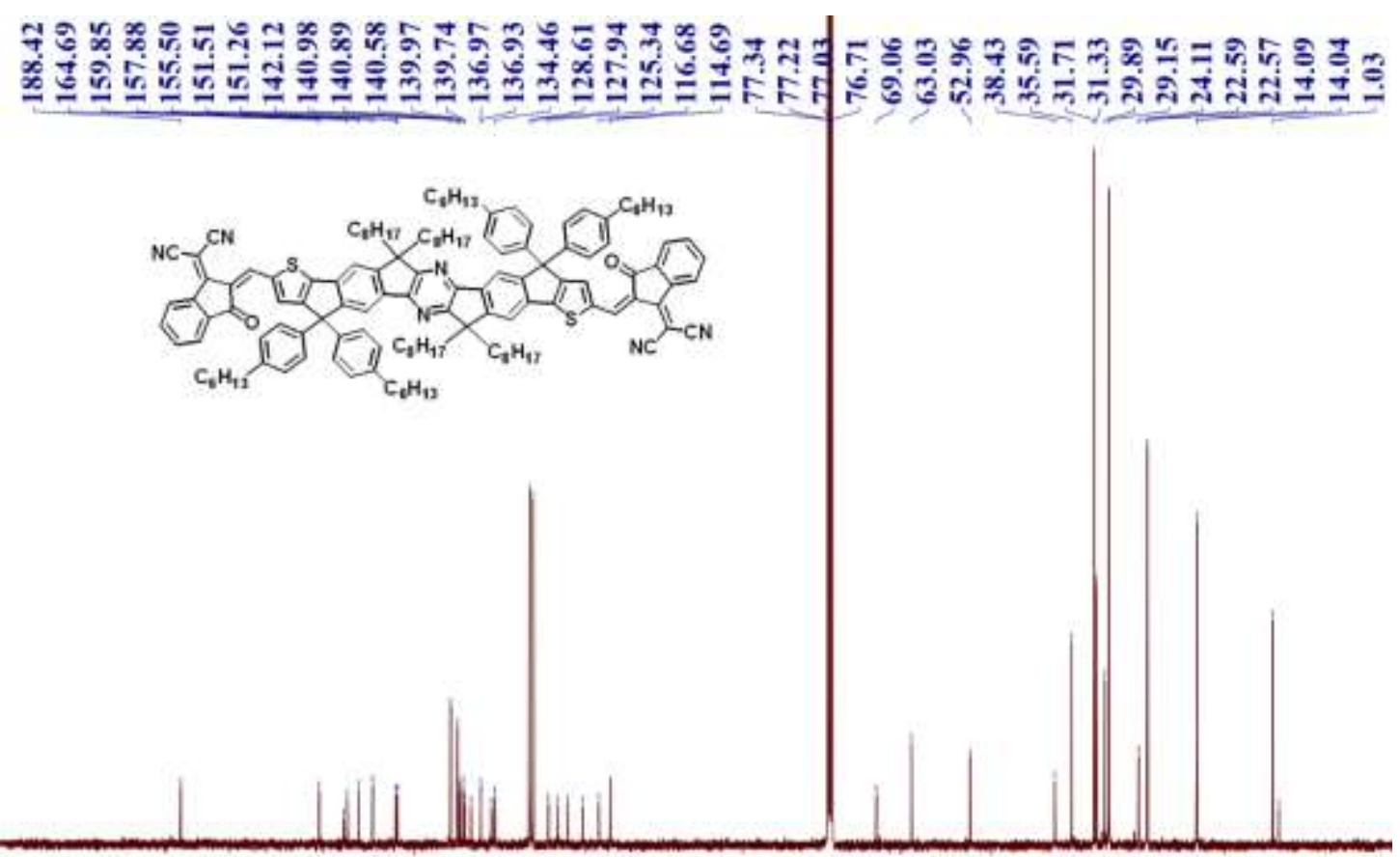

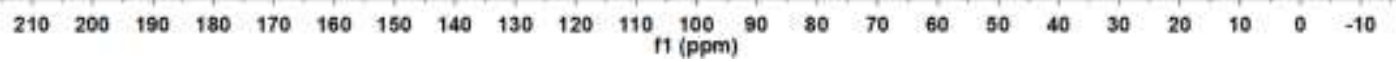

Figure S11. The ${ }^{13} \mathrm{C}$ NMR spectrum $\left(400 \mathrm{MHz}, \mathrm{CDCl}_{3}\right)$ of IPYT-IC.

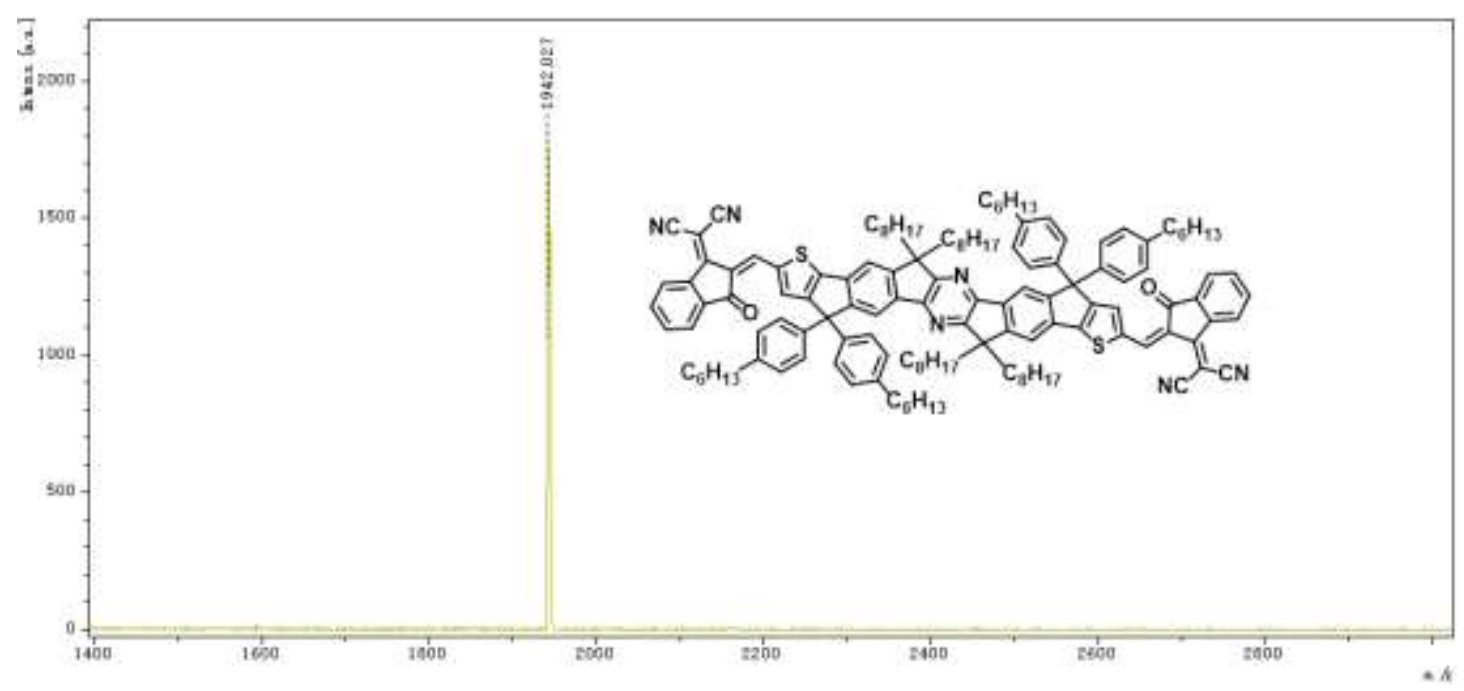

Figure S12. The MALDI-TOF mass spectrum of IPYT-IC. 


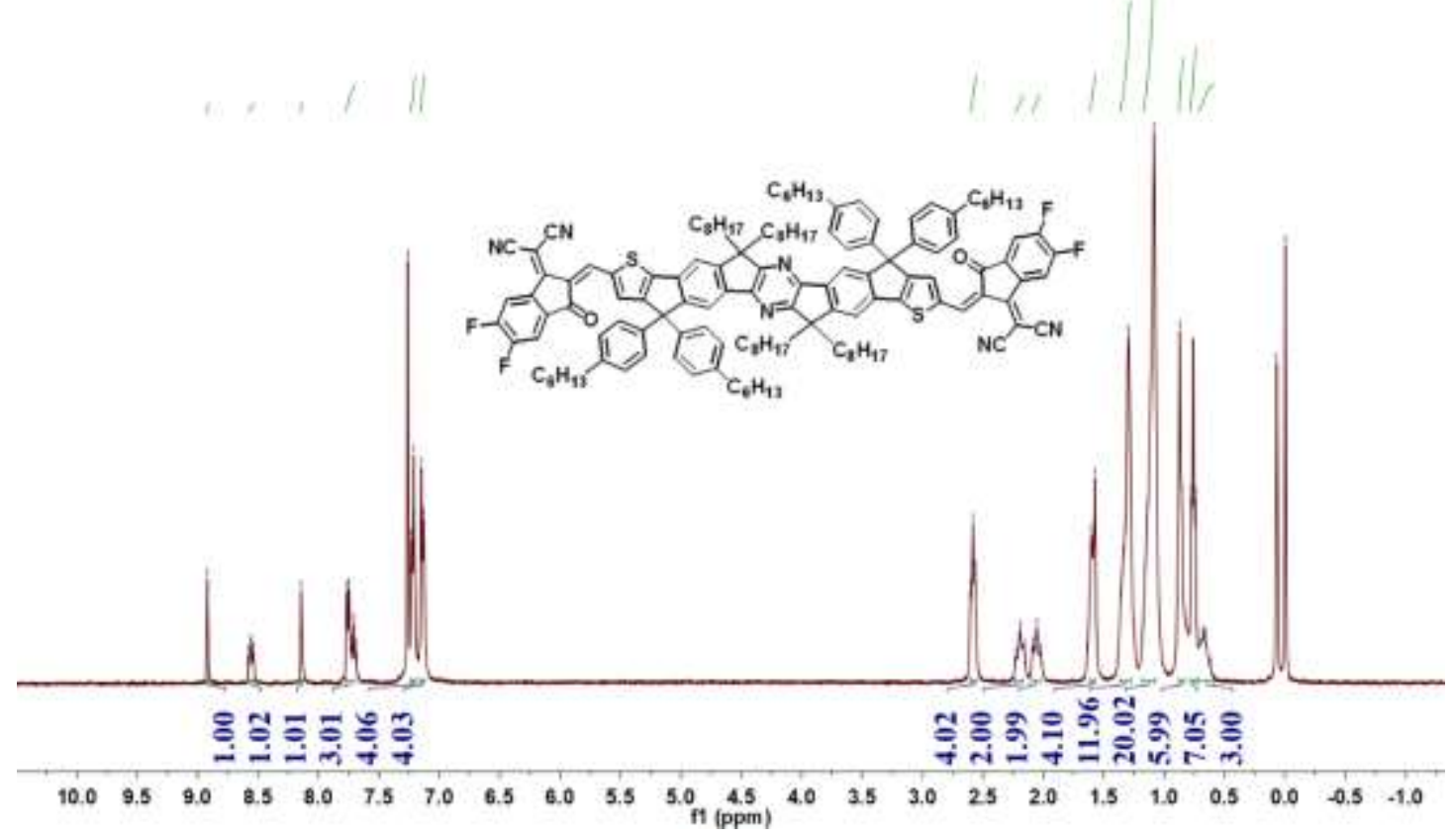

Figure S13. The ${ }^{1} \mathrm{H}$ NMR spectrum $\left(400 \mathrm{MHz}, \mathrm{CDCl}_{3}\right)$ of IPYT-ICF.

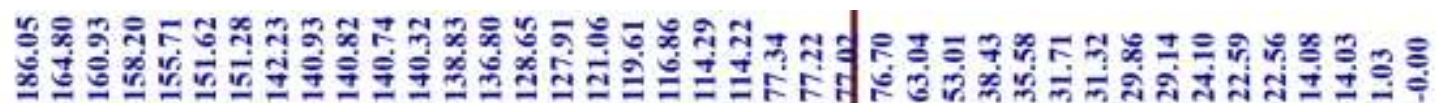
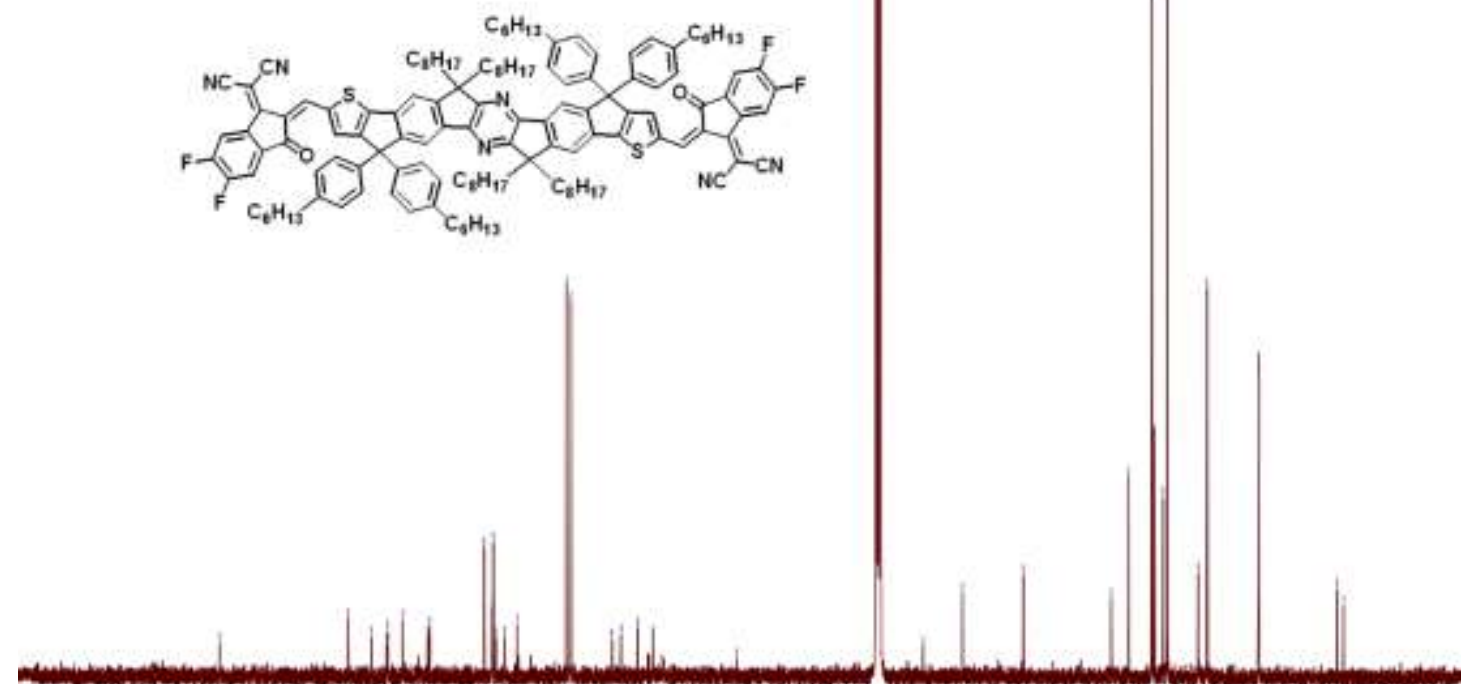

$\begin{array}{llllllllllllllllllllllllll}210 & 200 & 190 & 180 & 170 & 160 & 150 & 140 & 130 & 120 & 110 & 100 & 90 & 80 & 70 & 60 & 50 & 40 & 30 & 20 & 10 & 0 & -10\end{array}$

Figure S14. The ${ }^{13} \mathrm{C}$ NMR spectrum $\left(400 \mathrm{MHz}, \mathrm{CDCl}_{3}\right)$ of IPYT-ICF. 


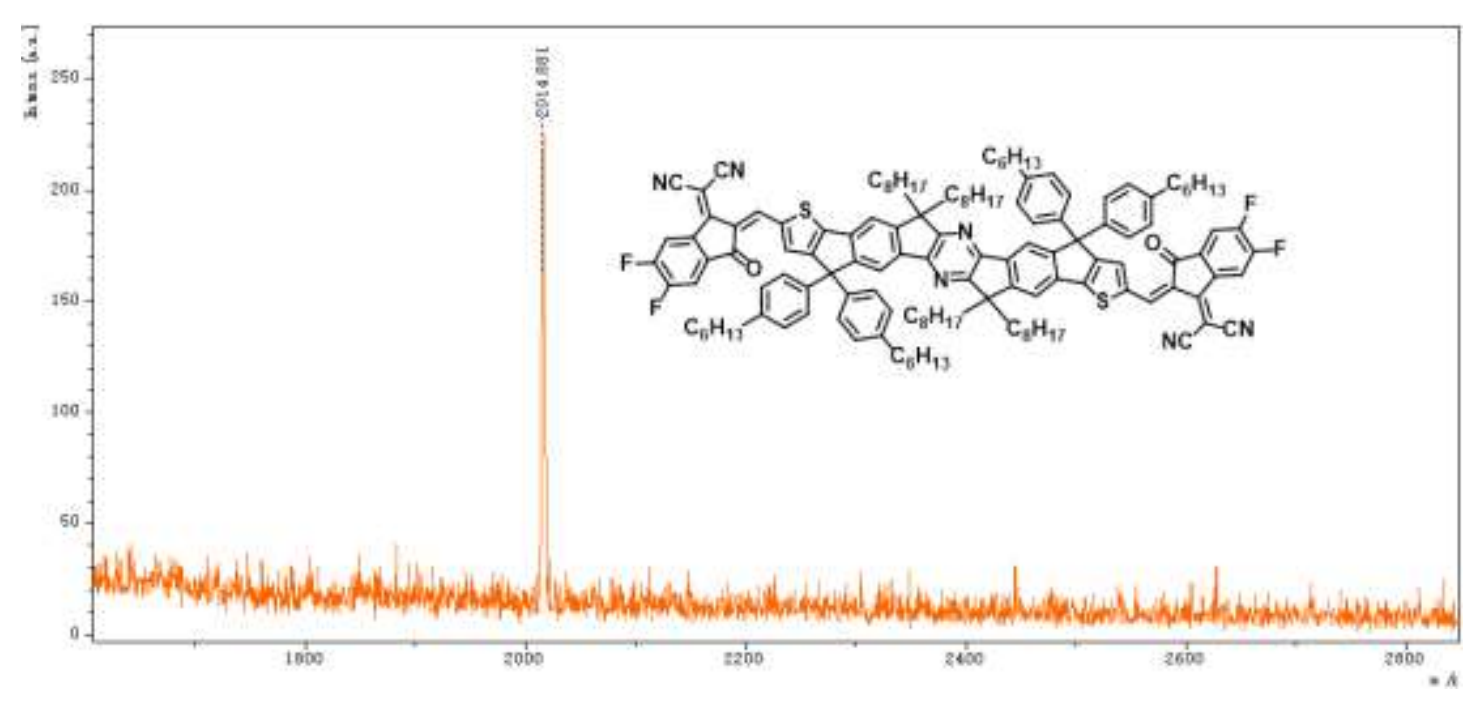

Figure S15. The MALDI-TOF mass spectrum of IPYT-ICF.

(a)

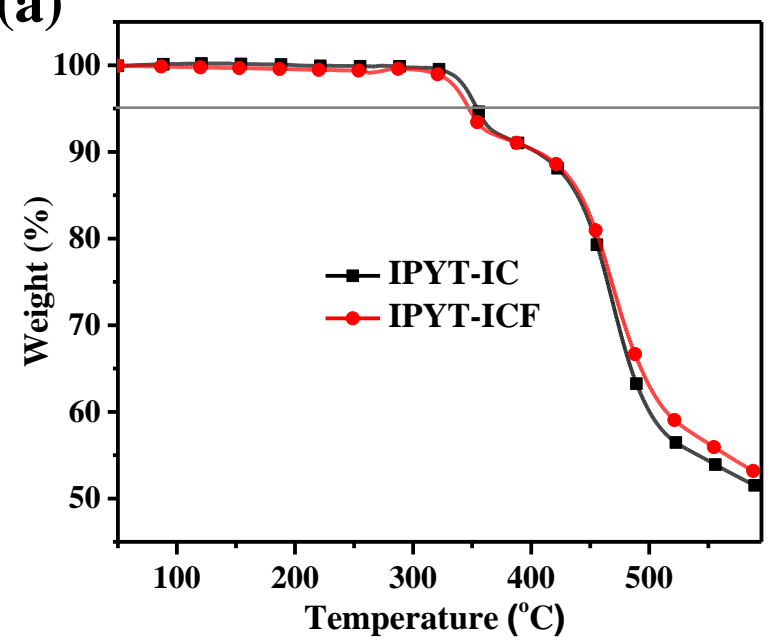

(b)

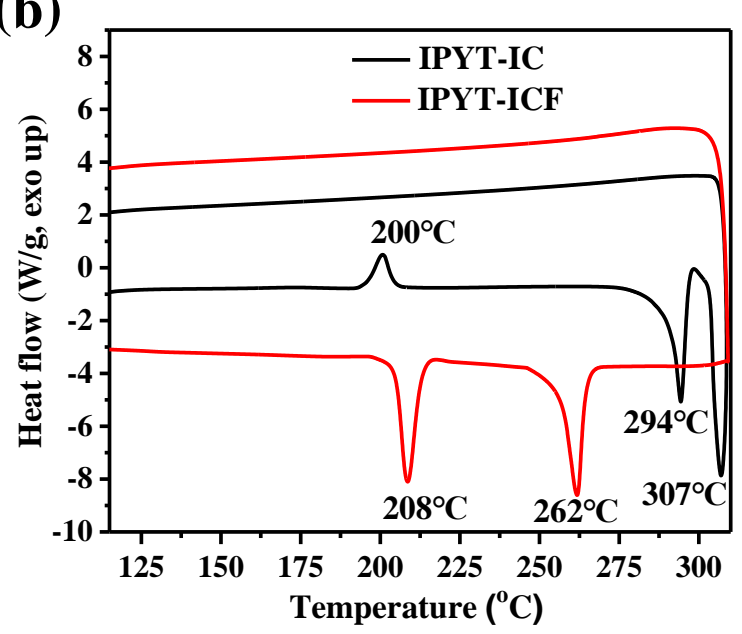

Figure S16. (a) TGA curves of IPYT-IC and IPYT-ICF under nitrogen atmosphere at a heating rate of $20{ }^{\circ} \mathrm{C}$ $\min ^{-1}$. (b) DSC curves of IPYT-IC and IPYT-ICF under nitrogen atmosphere at a heating rate of $5{ }^{\circ} \mathrm{C} \mathrm{min}^{-1}$. 


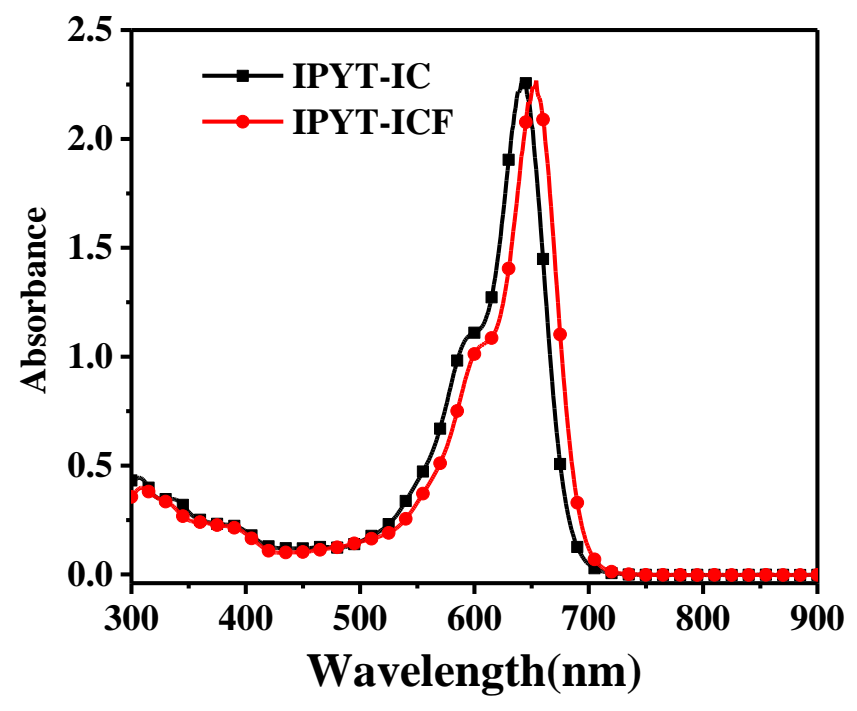

Figure S17. UV-vis absorption spectra of the two SMAs in a dilute chloroform solution $\left(10^{-5} \mathrm{M}\right)$.

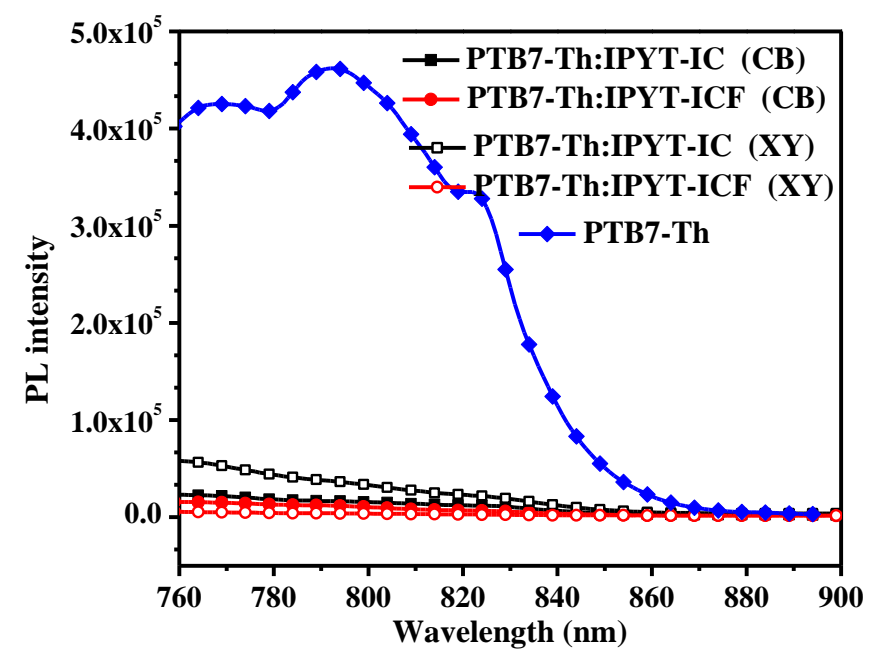

Figure S18. Photoluminescence spectra of the pure PTB7-Th film and the two blend films processed with XY and $\mathrm{CB}$ with an excited wavelength at $705 \mathrm{~nm}$. 
(a)

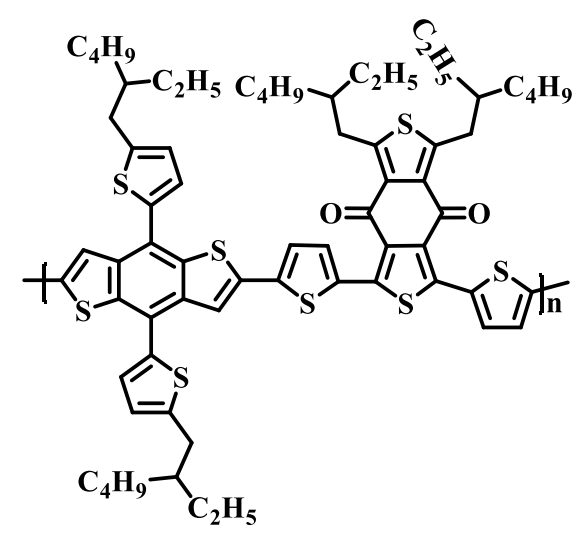

PBDB-T

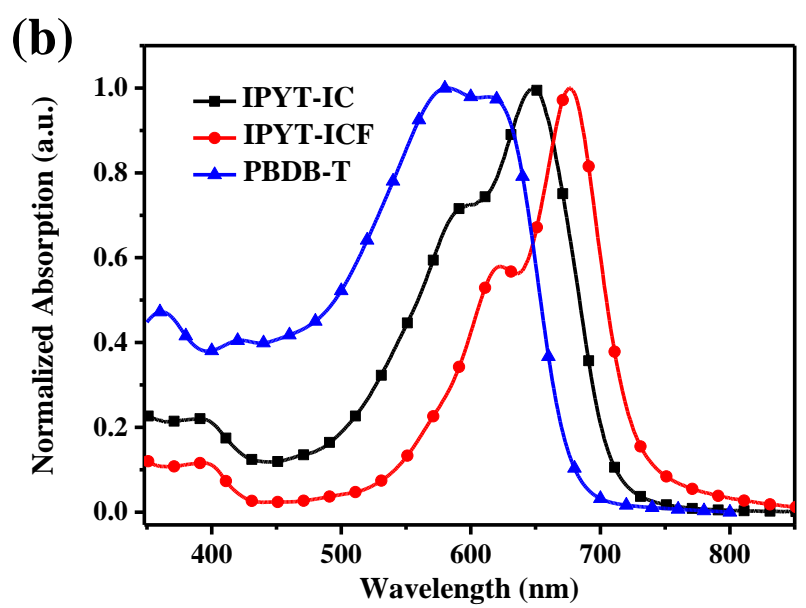

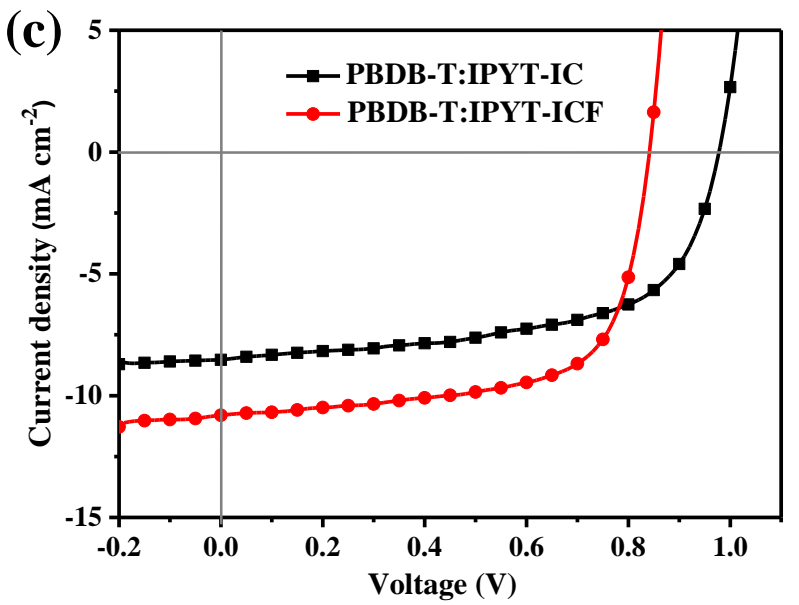

Figure S19. (a) Chemical structure of the medium polymer donor PBDB-T. (b) Absorption spectra of the medium polymer donor PBDB-T and the two SMAs as solid films. (c) The $J-V$ curves of the PSCs based on IPYT-IC and IPYT-ICF using PBDB-T as the donor with a D/A ratio of 1:1 and CB as a processing solvent.

Table S1. Photovoltaic performance of the PSCs based on PTB7-Th:IPYT-ICF with the different D/A ratio using $\mathrm{CB}$ as the processed solvent. ${ }^{a}$

\begin{tabular}{ccccc}
\hline $\mathrm{D} / \mathrm{A}$ & $V_{o c}(\mathrm{~V})$ & $J_{s c}\left(\mathrm{~mA} \mathrm{~cm}^{-2}\right)$ & $\mathrm{FF}(\%)$ & PCE $(\%)$ \\
\hline $1: 0.8$ & $0.76(0.76 \pm 0.00)$ & $14.60(14.67 \pm 0.11)$ & $51.4(51.7 \pm 0.70)$ & $5.73(5.67 \pm 0.12)$ \\
$1: 1$ & $0.76(0.76 \pm 0.00)$ & $14.57(14.29 \pm 0.51)$ & $55.8(54.9 \pm 0.90)$ & $6.18(6.11 \pm 0.06)$ \\
$1: 1.5$ & $0.79(0.78 \pm 0.01)$ & $14.29(14.19 \pm 0.40)$ & $61.3(60.4 \pm 1.10)$ & $6.90(6.60 \pm 0.33)$ \\
$1: 2$ & $0.78(0.77 \pm 0.02)$ & $12.52(12.22 \pm 0.34)$ & $61.8(60.9 \pm 0.50)$ & $6.04(5.94 \pm 0.13)$ \\
\hline
\end{tabular}

${ }^{a}$ The standard deviation was determined based on 5-7 independent devices. 
Table S2. Photovoltaic performance of the PSCs based on PTB7-Th:IPYT-ICF (1:1.5, by weight) with the different content of the additive $\mathrm{CN}$ using $\mathrm{CB}$ as the processed solvent. $^{a}$

\begin{tabular}{ccccc}
\hline $\mathrm{CN}(\mathrm{vol} \%)$ & $V_{o c}(\mathrm{~V})$ & $J_{s c}\left(\mathrm{~mA} \mathrm{~cm}^{-2}\right)$ & $\mathrm{FF}(\%)$ & PCE $(\%)$ \\
\hline 0 & $0.79(0.78 \pm 0.01)$ & $14.29(14.19 \pm 0.40)$ & $61.3(61.1 \pm 0.50)$ & $6.92(6.60 \pm 0.33)$ \\
0.5 & $0.78(0.78 \pm 0.01)$ & $11.32(11.13 \pm 0.33)$ & $65.6(64.8 \pm 0.40)$ & $5.82(5.77 \pm 0.07)$ \\
1 & $0.78(0.78 \pm 0.01)$ & $12.21(11.94 \pm 0.34)$ & $66.3(64.7 \pm 1.10)$ & $6.33(6.12 \pm 0.14)$ \\
2 & $0.77(0.77 \pm 0.00)$ & $12.30(12.09 \pm 0.45)$ & $63.8(63.1 \pm 1.10)$ & $6.06(5.84 \pm 0.26)$ \\
\hline
\end{tabular}

${ }^{a}$ The standard deviation was determined based on 5-8 independent devices.

Table S3. Photovoltaic performance of the PSCs based on the PTB7-Th:IPYT-ICF (1:1.5, by weight) with and without the additive (MN) using $\mathrm{XY}$ as the processed solvent. ${ }^{a}$

\begin{tabular}{ccccc}
\hline $\mathrm{MN}(\mathrm{vol} \%)$ & $V_{o c}(\mathrm{~V})$ & $J_{s c}\left(\mathrm{~mA} \mathrm{~cm}^{-2}\right)$ & FF $(\%)$ & PCE $(\%)$ \\
\hline 0 & $0.76(0.76 \pm 0.01)$ & $15.54(15.05 \pm 0.75)$ & $58.9(58.2 \pm 1.00)$ & $7.00(6.86 \pm 0.11)$ \\
0.8 & $0.77(0.76 \pm 0.01)$ & $14.60(14.51 \pm 0.26)$ & $61.1(59.8 \pm 1.10)$ & $6.87(6.68 \pm 0.14)$ \\
\hline
\end{tabular}

${ }^{a}$ The standard deviation was determined based on 6-10 independent devices.

Table S4. Photovoltaic performance of the PSCs based on PTB7-Th:IPYT-IC with the different D/A ratio, and additive content $(\mathrm{CN})$ using $\mathrm{CB}$ as the processed solvent. ${ }^{a}$

\begin{tabular}{|c|c|c|c|c|c|}
\hline Active layer & $\mathrm{CN}(\%)$ & $V_{o c}(\mathrm{~V})$ & $J_{s c}\left(\mathrm{mAcm}^{-2}\right)$ & FF $(\%)$ & $\operatorname{PCE}(\%)$ \\
\hline PTB7-Th:IPYT-IC = 1:1 & 0 & $\begin{array}{c}0.88 \\
(0.88 \pm 0.00)\end{array}$ & $\begin{array}{c}13.19 \\
(13.10 \pm 0.15)\end{array}$ & $\begin{array}{c}48.2 \\
(47.5 \pm 0.60)\end{array}$ & $\begin{array}{c}5.70 \\
(5.53 \pm 0.08)\end{array}$ \\
\hline PTB7-Th:IPYT-IC $=1: 1^{b}$ & 0 & $\begin{array}{c}0.88 \\
(0.88 \pm 0.00)\end{array}$ & $\begin{array}{c}12.26 \\
(12.04 \pm 0.30)\end{array}$ & $\begin{array}{c}47.1 \\
(46.6 \pm 0.70)\end{array}$ & $\begin{array}{c}5.08 \\
(5.00 \pm 0.11)\end{array}$ \\
\hline PTB7-Th:IPYT-IC = 1:1 & 0.5 & $\begin{array}{c}0.88 \\
(0.88 \pm 0.01)\end{array}$ & $\begin{array}{c}13.45 \\
(13.09 \pm 0.26)\end{array}$ & $\begin{array}{c}48.0 \\
(47.5 \pm 0.50)\end{array}$ & $\begin{array}{c}5.74 \\
(5.65 \pm 0.12)\end{array}$ \\
\hline PTB7-Th:IPYT-IC $=1: 1^{b}$ & 0.5 & $\begin{array}{c}0.88 \\
(0.88 \pm 0.00)\end{array}$ & $\begin{array}{c}12.50 \\
(12.27 \pm 0.23)\end{array}$ & $\begin{array}{c}46.2 \\
(46.5 \pm 0.50)\end{array}$ & $\begin{array}{c}5.11 \\
(6.05 \pm 0.11)\end{array}$ \\
\hline PTB7-Th:IPYT-IC = 1:1.5 & 0 & $\begin{array}{c}0.91 \\
(0.90 \pm 0.00)\end{array}$ & $\begin{array}{c}13.08 \\
(13.07 \pm 0.02)\end{array}$ & $\begin{array}{c}52.3 \\
(51.5 \pm 0.40)\end{array}$ & $\begin{array}{c}6.19 \\
(6.07 \pm 0.11)\end{array}$ \\
\hline
\end{tabular}

${ }^{a}$ The standard deviation was determined based on 6-10 independent devices. ${ }^{b}$ Thermal annealing under $130{ }^{\circ} \mathrm{C}$ for $10 \mathrm{~min}$. 